\title{
Aortic valve stenosis in community medical practice: Determinants of outcome and implications for aortic valve replacement
}

\author{
Joseph Malouf, MD, ${ }^{a}$ Thierry Le Tourneau, MD, ${ }^{a}$ Patricia Pellikka, MD, ${ }^{a}$ Thoralf M. Sundt, MD, \\ Christopher Scott, MS, ${ }^{\mathrm{c}}$ Hartzell V. Schaff, MD, ${ }^{\mathrm{b}}$ and Maurice Enriquez-Sarano, MD ${ }^{\mathrm{a}}$
}

Objective: To define the objective and subjective measures of aortic stenosis (AS) severity linked to survival after diagnosis in community practice.

\begin{abstract}
Methods: All 360 Olmsted County, Minnesota residents ( $74 \pm 14$ years; 44\% men) with AS diagnosed from 1988 to 1997 by echocardiography and without life-threatening comorbid conditions were enrolled. The presentation at first diagnosis, outcomes (mortality, heart failure, cardiac surgery), and coherence of guideline-based criteria for severe AS were analyzed.
\end{abstract}

Results: The presentation was challenging. Cardiac symptoms were frequent $(59 \%)$ and unassociated with the AS severity (all $P>.13$ ). Of the patients with severe AS, as determined by a valve area less than $1.0 \mathrm{~cm}^{2}, 67 \%$ had low gradient AS ( $\leq 40 \mathrm{~mm} \mathrm{Hg}$ ). An aortic valve area less than $1.0 \mathrm{~cm}^{2}$ was the only objective measure independently determining survival (adjusted risk ratio, 1.81; 95\% confidence interval [CI], 1.19-2.70; $P<.01$ ) and heart failure (adjusted risk ratio, 2.3; 95\% CI, 1.3-4.0; $P<.01$ ), even in patients with low-gradient AS and/ or an ejection fraction of $50 \%$ or greater. Excess mortality (vs expected mortality) occurred with an aortic valve area of less than $1.0 \mathrm{~cm}^{2}$ (risk ratio, $1.78 ; 95 \% \mathrm{CI}, 1.33-2.35 ; P<.001$ ) even without symptoms (risk ratio, 1.65 ; $95 \% \mathrm{CI}, 1.05-2.47 ; P=.02$ ). Aortic valve replacement, ultimately performed in only $45 \%$ of those with an aortic valve area less than $1.0 \mathrm{~cm}^{2}$, reduced mortality (risk ratio, $0.61 ; 95 \% \mathrm{CI}, 0.39-0.94 ; P=.02$ ) and heart failure (risk ratio, $0.29 ; 95 \% \mathrm{CI}, 0.13-0.64 ; P<.01$ ).

Conclusions: In community practice, AS affects elderly patients, and its presentation is challenging owing to the high frequency of low-gradient severe AS despite a normal ejection fraction and because symptoms are frequently not specific to AS. Consequently, aortic valve replacement is seldom performed despite its considerable benefit. Physicians should be aware that an aortic valve area of less than $1.0 \mathrm{~cm}^{2}$ predicts for unfavorable outcomes, irrespective of symptoms or gradient. Thus, such patients should undergo a thorough evaluation to detect those who could benefit from aortic valve replacement, despite their challenging presentation. (J Thorac Cardiovasc Surg 2012;144:1421-7)

Aortic stenosis (AS) in the current era is predominantly a degenerative disease of the elderly. ${ }^{1,2}$ Aortic valve replacement (AVR) is the only established treatment of $\mathrm{AS}^{3}$; however, recent clinical series ${ }^{4,5}$ have shown that AVR is inconsistently offered to these older patients. Although symptoms remain the main indication for AVR in patients with $\mathrm{AS},{ }^{3}$ the interpretation of symptoms, in particular, shortness of breath in the elderly, can be challenging, either because of lack of symptoms owing to inactivity or because of age-related confounders such as coronary artery disease or chronic lung disease that affect symptom reliability. ${ }^{4,6,7}$ Moreover, an often-held tenet is that in patients with severe AS, the absence

\footnotetext{
From the Divisions of Cardiovascular Diseases ${ }^{\mathrm{a}}$ and Cardiovascular Surgery ${ }^{\mathrm{b}}$ and Section of Biostatistics, ${ }^{\mathrm{c}}$ Mayo Clinic, Rochester, Minn.

This study was funded by the Mayo Foundation.

Disclosures: Authors have nothing to disclose with regard to commercial support.

Received for publication June 29, 2011; revisions received Aug 26, 2011; accepted

for publication Sept 26, 2011; available ahead of print Feb 16, 2012.

Address for reprints: Maurice Enriquez-Sarano, MD, Mayo Clinic, 200 First Street

Southwest, Rochester, MN 55905 (E-mail: sarano.maurice@mayo.edu). $0022-5223 / \$ 36.00$

Copyright (c) 2012 Published by Elsevier Inc. on behalf of The American Association for Thoracic Surgery

doi:10.1016/j.jtcvs.2011.09.075
}

of symptoms implies a low risk. ${ }^{8}$ However, this remains unproved. Indeed, recent natural history studies of asymptomatic severe AS reported 5-year survival of $83 \%,{ }^{9} 60 \%,{ }^{6}$ or $38 \%,{ }^{10}$ which compared with the expected survival ranged from normal life expectancy to notable or even excess mortality. Uncertainty regarding AS hemodynamic severity is another major reason for not performing AVR because of increased operative mortality and morbidity in the elderly. ${ }^{5}$ Accurate grading of AS severity is therefore crucial for the decision to recommend AVR. ${ }^{7}$ However, objective assessment of AS severity has also been uncertain. Previous studies used various surrogates of AS severity that were not always concordant, ${ }^{6,9,10}$ and no formal comparison has been made of the outcome predictive strength of the various AS indexes and thresholds used, particularly those proposed by the guidelines. The traditional aortic valve area (AVA), supposedly directly measuring lesion severity and a standard for clinical management, in particular, lacks validation as an AS outcome determinant. Thus, several unconventional indexes have been proposed as superior measures of AS severity but lack intrinsic and comparative outcome analysis. ${ }^{11,12}$ 


$$
\begin{aligned}
& \text { Abbreviations and Acronyms } \\
& \text { AS }=\text { aortic stenosis } \\
& \text { AVA }=\text { aortic valve area } \\
& \text { AVR }=\text { aortic valve replacement } \\
& \mathrm{CHF}=\text { congestive heart failure } \\
& \mathrm{EF}=\text { ejection fraction } \\
& \mathrm{MnG}=\text { mean gradient } \\
& \mathrm{RR}=\text { risk ratio }
\end{aligned}
$$

To complete these knowledge gaps and to reduce selection bias, we conducted a community (residents of Olmsted County, Minn) cohort study, enrolling all patients diagnosed with AS in a geographically defined area. Our aim was to define the objective and subjective measures of AS severity that linked to survival after diagnosis.

\section{METHODS}

\section{Study Patients}

In Olmsted County, Minnesota, Mayo Clinic personnel perform all cardiology services, including echocardiography, allowing comprehensive identification of valvular diseases, reliably, compared with systematic population studies. ${ }^{2}$ Although the Mayo Clinic is a referral center, Olmsted County residents represent our community practice. The echocardiographic results are prospectively entered into a database from which all Olmsted County, Minnesota, residents (in- or outpatient) with a first diagnosis of native AS (mild or greater, valve area $<2.0 \mathrm{~cm}^{2}$ and $\mathrm{MnG} \geq 10 \mathrm{~mm}$ $\mathrm{Hg}$ ) from January 1, 1988 to December 31, 1997, and at most mild aortic regurgitation, were retrospectively identified. Of the 491 residents meeting these criteria, 131 were excluded (age, $<18$ years; $\mathrm{n}=19$, life-threatening comorbid conditions at diagnosis, $\mathrm{n}=87$; denied research authorization, $\mathrm{n}=23$ ). The remaining 360 patients represent all AS cases diagnosed in the entire community and formed the study group. The Mayo Institutional Review Board approved the present study.

\section{Clinical Data}

The baseline clinical variables were abstracted from the medical records as noted by the personal physicians. Symptoms were classified as any cardiac symptoms (any dyspnea, chest discomfort, syncope or near syncope, or fatigue), typical AS-associated symptoms (syncope or near syncope, dyspnea, and probable or classic angina), severe AS-associated symptoms (syncope, classic angina, and class III-IV dyspnea), and class III-IV symptoms for dyspnea or classic angina class III-IV. Follow-up information was obtained from the medical records, mailed questionnaires, or death certificates and from scripted telephone interviews with the patients or physicians.

\section{Echocardiographic Doppler Measurements}

Index echocardiographic data were captured electronically without alteration from our prospective echocardiographic database. AS severity was assessed using Doppler-derived conventional (AVA, mean gradient [MnG], and peak velocity) and nonconventional (aortic valve resistance and stroke work loss) measures. AVA, calculated using the continuity equation, ${ }^{13}$ was also indexed to the body surface area. From the guidelines, ${ }^{3}$ mild, moderate, and severe stenosis was defined as AVA 1.5 to $2.0 \mathrm{~cm}^{2}$, 1.0 to $1.5 \mathrm{~cm}^{2}$, and less than $1.0 \mathrm{~cm}^{2}$, respectively. A peak velocity greater than $4 \mathrm{~m} / \mathrm{s}$ and $\mathrm{MnG}$ greater than $40 \mathrm{~mm} \mathrm{Hg}$ are guideline-based ${ }^{3}$ thresholds for severe AS. Valve resistance and left ventricular stroke work loss were derived. ${ }^{12}$

\section{Statistical Analysis}

Continuous variables are reported as the mean \pm standard deviation. Group comparisons used analysis of variance or the Kruskal-Wallis test. Categorical variables were reported as percentages compared using the chi-square test. The primary endpoint was survival after diagnosis under medical management (censored at AVR). A secondary endpoint was congestive heart failure (CHF) development. Event rates were estimated using the Kaplan-Meier method and compared using the log-rank test. The expected survival in the age- and sex-matched Minnesota white population (US census bureau) was compared with the observed survival using a 1-sample log-rank test. A predictive power comparison for the outcome determinants used the c-statistic (measure of concordance between the observed and predicted survival from Cox proportional hazards models) similar to the area under the curve for binary endpoints. ${ }^{14}$ Standard errors from 1000 bootstrap samples constructed the $95 \%$ confidence intervals (CIs) to test for differences between predictors. Multivariate models used Cox proportional hazards. AVR during follow-up was tested as a time-dependent covariate in the Cox proportional hazards models.

\section{RESULTS \\ Baseline Characteristics}

The baseline characteristics are summarized in Table 1. The AVA was less than $1.0 \mathrm{~cm}^{2}$ in $96(27 \%), 1.0$ to 1.49 $\mathrm{cm}^{2}$ in $175(49 \%)$, and $1.5 \mathrm{~cm}^{2}$ or greater in 89 patients $(25 \%)$. A MnG greater than $40 \mathrm{~mm} \mathrm{Hg}$ and peak velocity greater than $4 \mathrm{~m} / \mathrm{s}$ was present in $9 \%$ and $10 \%$, respectively. No difference (apart from age) was found in the clinical characteristics among the AVA groups, particularly regarding the symptoms (Table 1). Although all echocardiographic measures of AS severity grossly followed the AVA (Table 1), agreement between the markers of severe AS was imperfect. Most patients with a MnG greater than $40 \mathrm{~mm} \mathrm{Hg}(94 \%)$ or peak velocity greater than $4 \mathrm{~m} / \mathrm{s}(95 \%)$ also had an AVA of less than $1.0 \mathrm{~cm}^{2}$. However, most patients with an AVA of less than $1.0 \mathrm{~cm}^{2}$ had a MnG of $40 \mathrm{~mm} \mathrm{Hg}$ or less $(67 \%)$ or even, frequently, a MnG of less than $30 \mathrm{~mm} \mathrm{Hg} \mathrm{(32 \% )}$ and peak velocity of $4 \mathrm{~m} / \mathrm{s}$ or less $(64 \%)$. Thus, an AVA less than $1.0 \mathrm{~cm}^{2}$ was the only marker of severe AS in 60 $(63 \%)$ of 96 "discordant" patients. Patients with discordant versus concordant stenosis markers had a lower stroke volume index ( $34 \pm 8$ vs $\left.41 \pm 9 \mathrm{~mL} / \mathrm{m}^{2}, P<.01\right)$ and ejection fraction (EF, $54 \% \pm 16 \%$ vs $60 \% \pm 13 \%, P=.048)$, although most $(67 \%)$ had an EF greater than $50 \%$.

\section{Outcomes}

The follow-up period, available for all (99.7\%) but 1 patient, was $7.5 \pm 4.2$ years, with 220 deaths noted (10-year survival, $42 \% \pm 3 \%$ ), including 170 receiving medical treatment (10-year survival, $37 \% \pm 4 \%)$. In 131 patients, AVR was ultimately performed (10-year survival, $53 \pm$ $4 \%$ ), and 301 patients either died or underwent valve replacement (10-year survival, $82 \% \pm 2 \%$ ).

\section{Survival During Medical Management}

Clinically, of the symptom categories (any cardiac, typical, severe, and class III-IV), only class III-IV symptoms 
TABLE 1. Baseline clinical and echocardiographic Doppler characteristics

\begin{tabular}{|c|c|c|c|c|c|}
\hline \multirow[b]{2}{*}{ Variable } & \multirow[b]{2}{*}{ Overall population $(n=360)$} & \multicolumn{3}{|c|}{$\operatorname{AVA}\left(\mathrm{cm}^{2}\right)$} & \multirow[b]{2}{*}{$P$ value } \\
\hline & & $<1.0(\mathrm{n}=96)$ & $1-1.5(n=175)$ & $\geq 1.5(n=89)$ & \\
\hline \multicolumn{6}{|l|}{ Baseline clinical characteristics } \\
\hline Age (yr) & $74 \pm 14$ & $77 \pm 15$ & $74 \pm 12$ & $69 \pm 15$ & $<.001$ \\
\hline Men (n) & $158(44)$ & $43(45)$ & $73(42)$ & $42(47)$ & .68 \\
\hline \multicolumn{6}{|l|}{ Symptoms (n) } \\
\hline Any cardiac* & $211(59)$ & $62(65)$ & $104(60)$ & $45(51)$ & .20 \\
\hline Typical $\dagger$ & $165(46)$ & $54(56)$ & $76(43)$ & $35(39)$ & .25 \\
\hline Severe $\ddagger$ & $74(21)$ & $21(21)$ & $37(21)$ & $17(19)$ & .15 \\
\hline Class III/IV $\S$ & $41(11)$ & $16(17)$ & $15(9)$ & $10(11)$ & .13 \\
\hline Atrial fibrillation (n) & $65(18)$ & $19(20)$ & $31(18)$ & $15(17)$ & .86 \\
\hline Hypertension (n) & $208(58)$ & $52(54)$ & $100(57)$ & $56(63)$ & .47 \\
\hline Coronary disease (n) & $101(28)$ & $25(26)$ & $47(27)$ & $29(33)$ & .54 \\
\hline Comorbidity index & $4.4 \pm 3.1$ & $4.4 \pm 3.1$ & $4.4 \pm 3.2$ & $4.7 \pm 2.8$ & .54 \\
\hline Systolic blood pressure (mm Hg) & $146 \pm 22$ & $147 \pm 23$ & $145 \pm 22$ & $149 \pm 21$ & .57 \\
\hline Creatinine $(\mathrm{mg} / \mathrm{dL})$ & & & & & .62 \\
\hline Mean & 1.1 & 1.0 & 1.1 & 1.1 & \\
\hline Interquartile range & $0.9-1.3$ & $0.9-1.4$ & $0.9-1.2$ & $0.9-1.3$ & \\
\hline \multicolumn{6}{|c|}{ Echocardiographic Doppler measurements } \\
\hline Valve area $\left(\mathrm{cm}^{2}\right)$ & $1.23 \pm 0.36$ & $0.79 \pm 0.14$ & $1.23 \pm 0.14$ & $1.71 \pm 0.13$ & - \\
\hline Indexed valve area $\left(\mathrm{cm}^{2} / \mathrm{m}^{2}\right)$ & $0.68 \pm 0.22$ & $0.45 \pm 0.10$ & $0.68 \pm 0.11$ & $0.94 \pm 0.19$ & $<.001$ \\
\hline Mean gradient $(\mathrm{mm} \mathrm{Hg})$ & $22 \pm 14$ & $36 \pm 19$ & $17 \pm 7$ & $14 \pm 4$ & $<.001$ \\
\hline Peak velocity $(\mathrm{m} / \mathrm{s})$ & $2.9 \pm 0.82$ & $3.8 \pm 0.93$ & $2.7 \pm 0.48$ & $2.4 \pm 0.37$ & $<.001$ \\
\hline Aortic velocity ratio & $0.37 \pm 0.11$ & $0.25 \pm 0.06$ & $0.38 \pm 0.07$ & $0.48 \pm 0.09$ & $<.001$ \\
\hline Valve resistance $\left(\right.$ dynes $/ \mathrm{s} / \mathrm{cm}^{-5}$ ) & $121 \pm 89$ & $225 \pm 115$ & $95 \pm 25$ & $61 \pm 10$ & $<.001$ \\
\hline Stroke work loss $(\%)$ & $13 \pm 7$ & $19 \pm 8$ & $11 \pm 4$ & $9 \pm 3$ & $<.001$ \\
\hline Ejection fraction $(\%)$ & $60 \pm 13$ & $56 \pm 15$ & $61 \pm 11$ & $60 \pm 12$ & .12 \\
\hline
\end{tabular}

Data presented as mean \pm standard deviation or numbers, with percentages in parentheses. AVA, Aortic valve area. *Any cardiac symptoms: typical or atypical chest pain or discomfort, dyspnea of any degree, syncope or near syncope, or fatigue. †Typical symptoms: syncope or near syncope, dyspnea of any degree and probable or typical angina. $\ddagger$ Severe symptoms: syncope, typical angina, or class III-IV dyspnea. §Class III or IV dyspnea (New York Heart Association classification) or typical angina (Canadian classification).

predicted survival during medical management (risk ratio [RR], 2.77; 95\% CI, 1.48-5.19; $P=.001$ on univariate analysis; and RR, 1.81; 95\% CI, 1.19-2.77; $P=.009$, adjusting for age, sex, Charlson comorbidity index, history of atrial fibrillation, hypertension, coronary disease, and stroke/transient ischemic attack). Forcing into the models, lower symptom categories or individual symptoms yielded no additional marker of survival or model strength (all $P>$.10). However, class III-IV symptoms were insensitive in predicting mortality because they were present in only 29 $(17 \%)$ of those who died during follow-up.

Of the Doppler echocardiographic measures of AS severity, on univariate analysis, AVA less than $1.0 \mathrm{~cm}^{2}$ (RR, 3.27; 95\% CI, 2.33-4.61; $P<.001), \mathrm{MnG}$ greater than $40 \mathrm{~mm} \mathrm{Hg}$ (RR, $2.47 ; 95 \% \mathrm{CI}, 1.32-4.61 ; P=.012$ ), and peak velocity greater than $4 \mathrm{~m} / \mathrm{s}(\mathrm{RR}, 2.21 ; 95 \% \mathrm{CI}, 1.18-3.79 ; P=.016)$ predicted survival during medical management. Comparisons using c-statistics showed that for predicting survival, an AVA less than $1.0 \mathrm{~cm}^{2}$ is superior to $\mathrm{MnG}$ greater than $40 \mathrm{~mm} \mathrm{Hg}(P<.001)$ or peak velocity greater than $4 \mathrm{~m} / \mathrm{s}$ $(P<.001)$. An indexed $\left(<0.6 \mathrm{~cm}^{2} / \mathrm{m}^{2}\right)$ versus unindexed $\left(<1.0 \mathrm{~cm}^{2}\right)$ AVA did not add predictive power $(P=.13)$. The aortic velocity ratio, stroke work loss, and valve resistance were less powerful predictors of survival than the AVA (all $P<.01)$. On multivariate analysis, an AVA less than 1.0 $\mathrm{cm}^{2}$ was the only measure of AS severity independently predictive of survival during medical management. Adjusting for age, sex, comorbidity score, history of hypertension, atrial fibrillation, coronary disease, and stroke/transient ischemic attack, an AVA less than $1.0 \mathrm{~cm}^{2}$ independently predicted survival (adjusted RR, 1.81; 95\% CI, 1.19-2.70; $P<.01$ ), along with EF (adjusted RR, 0.98; 95\% CI, 0.967-0.99; per 1-point increase; $P<.01)$ and class III-IV symptoms (adjusted RR, 1.69; 95\% CI, 1.08-2.56; $P=.023$ ).

An AVA less than $1.0 \mathrm{~cm}^{2}$ was associated with lower 5- and 8 -year survival during medical management $(40 \% \pm$ $6 \%$ and $18 \% \pm 6 \%$, respectively) compared with an AVA of 1.0 to $1.5 \mathrm{~cm}^{2}(73 \% \pm 3 \%$ and $54 \% \pm 4 \%$, respectively) or an AVA of $1.5 \mathrm{~cm}^{2}$ or greater $(76 \% \pm 5 \%$ and $61 \% \pm 6 \%$, respectively; $P<.001$; Figure 1 ). Survival with an AVA of 1.0 to $1.5 \mathrm{~cm}^{2}$ and an AVA of $1.5 \mathrm{~cm}^{2}$ or greater was not different $(P=.25)$. With similar adjustment, an indexed AVA of less than $0.6 \mathrm{~cm}^{2} / \mathrm{m}^{2}$ predicted survival (adjusted RR, 1.63; 95\% CI, 1.11-2.36; $P=.01$ ) equal to that of unindexed AVA but did not add predictive power $(P>.10)$. Symptoms less severe than class III-IV, 


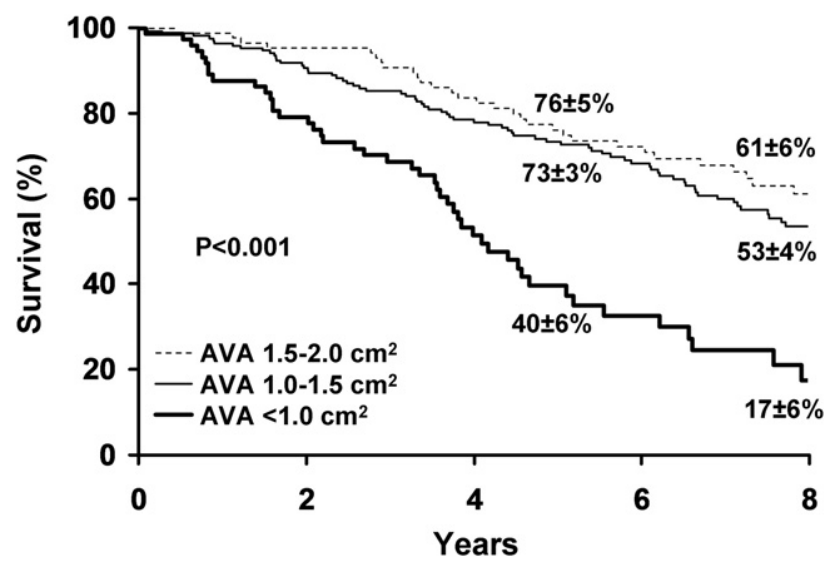

FIGURE 1. Survival during medical management of Olmsted County, Minnesota, residents after the diagnosis of aortic stenosis $(A S)$ according to baseline aortic valve area $(A V A)$. The numbers along each curve indicate the survival at 5 and 8 years. Note the excess mortality associated with an AVA less than $1.0 \mathrm{~cm}^{2}$.

irrespective of classification (cardiac, typical, or severe) did not add predictive power (all $P>.20$ ).

The observed versus expected survival rates were compared, stratified by functional class and an AVA less than $1.0 \mathrm{~cm}^{2}$ (Figure 2), with the RRs of the observed/expected mortality listed in Table 2. Class III-IV symptoms were associated with similar excess mortality with an AVA of less than $1.0 \mathrm{~cm}^{2}$ or $1.0 \mathrm{~cm}^{2}$ or greater However, the entire group of patients with an AVA of $1.0 \mathrm{~cm}^{2}$ or greater had no excess mortality. In contrast, the patients with an AVA of less than $1.0 \mathrm{~cm}^{2}$ had uniform excess mortality versus expected with RRs close to 2.0, irrespective of symptoms, even with an $\mathrm{EF}$ of $50 \%$ or greater or MnG less than 40 mm Hg $(P=.02)$. Class III-IV symptoms identified $11 \%$ of patients as at a high risk of death versus $27 \%$ by an AVA less than $1.0 \mathrm{~cm}^{2}$. The c-statistics showed that an AVA less than $1.0 \mathrm{~cm}^{2}$ predicted survival better than class III-IV symptoms $(P=.05)$. However, class III-IV symptoms showed greater specificity $(P<.0001)$ and an AVA less than $1.0 \mathrm{~cm}^{2}$ greater sensitivity $(P=.003)$ in predicting mortality.

\section{CHF With Medical Management}

With conservative management, 80 patients developed CHF (10-year incidence, $39 \% \pm 4 \%$ ). On multivariate analysis, adjusting for age, atrial fibrillation, and comorbidity, the EF (adjusted RR, 0.97; 95\% CI, 0.96-0.99, per 1-point increase; $P<.01$ ) and an AVA less than $1.0 \mathrm{~cm}^{2}$ (adjusted RR, 2.3; 95\% CI, 1.3-4.0; $P<.01$; Figure 3) independently predicted CHF during follow-up, with a borderline effect of class III-IV symptoms (adjusted RR, 1.82; $95 \%$ CI, $0.95-3.3 ; P=.07$ ). No other symptomatic category or objective measure of AS severity predicted CHF (all $P>.10$ ). The indexed AVA predicted CHF but did not add to the models with unindexed AVA $(P=.77)$. For predicting CHF, an AVA less than $1.0 \mathrm{~cm}^{2}$ was superior to the $\mathrm{MnG}$, peak velocity, and stroke work loss (all $P<.06$ ) but similar to an indexed AVA less than $0.6 \mathrm{~cm}^{2} / \mathrm{m}^{2}(P=.67)$.

\section{AVR and Outcome}

AVR was performed in 131 patients (at age $72 \pm 12$ years) and $69(53 \%)$ underwent concomitant coronary
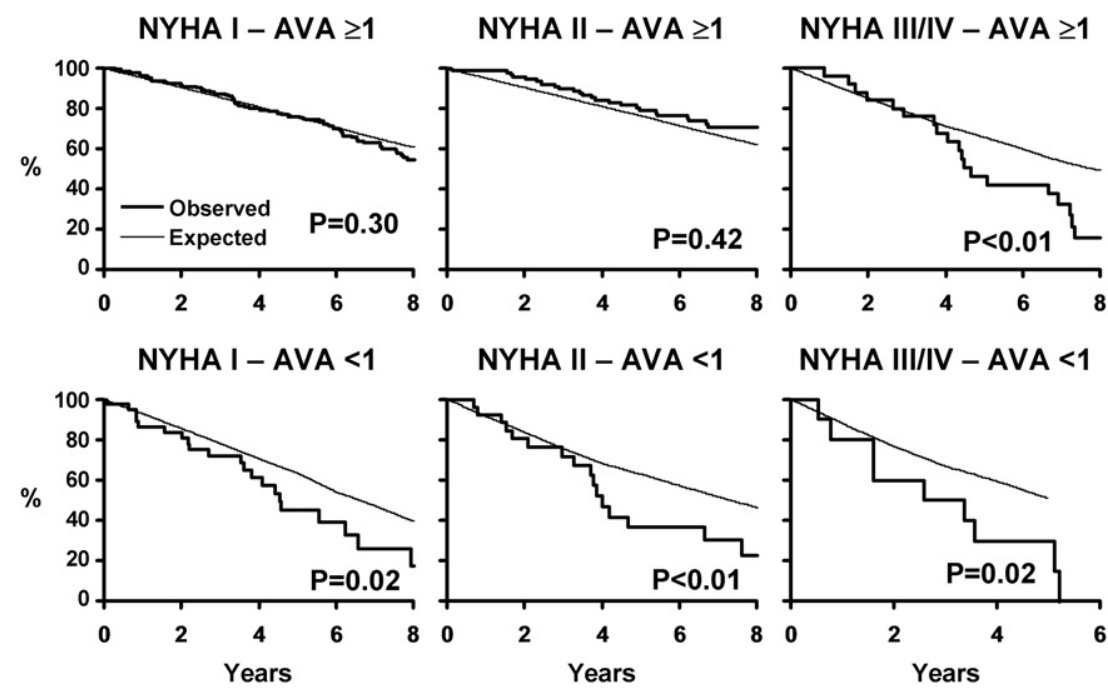

NYHA III/IV - AVA $<1$

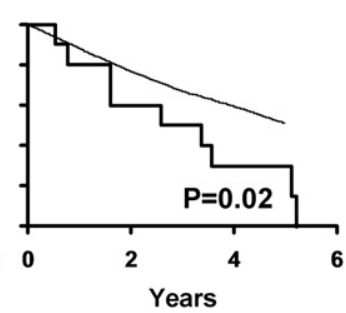

FIGURE 2. Survival during medical management in Olmsted County, Minnesota, residents after diagnosis of aortic stenosis (AS) compared with the expected survival specific to each subset, according to aortic valve area $(A V A)\left(<1.0\right.$ or $\left.\geq 1.0 \mathrm{~cm}^{2}\right)$ and functional class at diagnosis. Left, patients in functional class I (no angina or dyspnea); Middle, patients in class II (minimal angina or dyspnea); and Right, patients in class III-IV (severe angina or dyspnea). Observed survival (thick line) and expected survival (thin line) shown with 5-year rates indicated (bold, observed; thin italicized, expected), and $P$ values refer to their comparison. Note, that class III-IV symptoms were associated with excess mortality, irrespective of AS severity. Also, patients with AVA less than $1.0 \mathrm{~cm}^{2}$ incurred excess mortality compared with that expected in those with severe, minimal, or even absent symptoms of angina and dyspnea. 
TABLE 2. Relative risk of excess mortality (compared with expected mortality in Minnesota whites) after diagnosis of aortic stenosis according to aortic valve area and symptoms at diagnosis

\begin{tabular}{lcccc}
\hline & & \multicolumn{3}{c}{ Functional symptom class* } \\
\cline { 3 - 5 } AVA $\left(\mathbf{c m}^{2}\right)$ & Overall cohort & I & II & III-IV \\
\hline$\geq 1.0$ & & & & \\
Risk ratio & 1.11 & 1.14 & 0.87 & 1.81 \\
$95 \%$ CI & $0.92-1.33$ & $0.88-1.45$ & $0.60-1.22$ & $1.10-2.80$ \\
$P$ value & .25 & .30 & .42 & $<.01$ \\
$<1.0$ & & & & \\
Risk ratio & 1.78 & 1.65 & 1.81 & 2.17 \\
$95 \%$ CI & $1.33-2.35$ & $1.05-2.47$ & $1.09-2.83$ & $1.03-4.13$ \\
$P$ value & $<.001$ & .02 & $<.01$ & .02 \\
\hline
\end{tabular}

Data are presented as the risk ratio of observed to expected survival, with $95 \% \mathrm{CIs}$ and corresponding $P$ value. AVA, Aortic valve area; $C I$, confidence interval. *Class I, those with no angina and no dyspnea; class II, those with minimal angina or dyspnea; and class III-IV, those with severe dyspnea or angina at diagnosis.

bypass grafting. Most patients had cardiac symptoms before surgery $(92 \%)$ but so did $67 \%$ of unoperated patients. After valve replacement, 50 patients died, including 4 (3\%) perioperatively. AVR was ultimately performed in $43(45 \%)$ of $96,58(33 \%)$ of 175 , and $30(34 \%)$ of 89 patients with an AVA less than $1.0,1$ to 1.5 , and $1.5 \mathrm{~cm}^{2}$ or greater at diagnosis, representing a 5-year incidence (accounting for those remaining at risk) of $55 \% \pm 7 \%, 17 \% \pm 3 \%$, and $9 \% \pm$ $3 \%(P<.001)$. Adjusting for age, sex, comorbidity, atrial fibrillation, EF, and class III-IV symptoms, AVR was performed more frequently with an AVA less than $1.0 \mathrm{~cm}^{2}$ (adjusted RR, 2.8; 95\% CI, 1.6-4.6; $P<.001$ ) and $\mathrm{MnG}$ of $40 \mathrm{~mm} \mathrm{Hg}$ or greater (adjusted RR, 5.8; 95\% CI, 3.0$11.1 ; P<.001)$. Unoperated versus operated patients with an AVA less than $1.0 \mathrm{~cm}^{2}$ had a lower MnG $(29 \pm 15 \mathrm{vs}$ $45 \pm 20 \mathrm{~mm} \mathrm{Hg}, P<.001)$, were older $(84 \pm 11$ vs $68 \pm$ 15 years, $P<.001)$, and were more often women $(72 \%$ vs

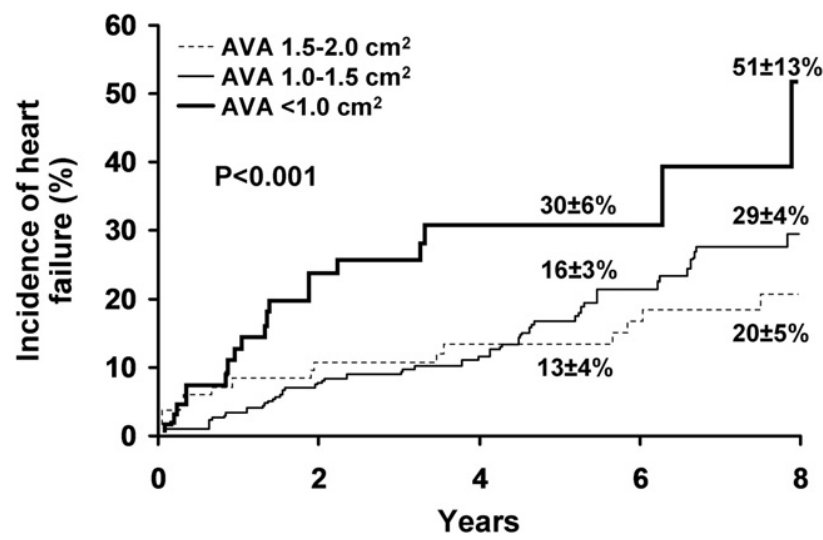

FIGURE 3. Incidence of congestive heart failure $(\mathrm{CHF})$ during medical management in Olmsted County, Minnesota, residents after the diagnosis of aortic stenosis (AS) according to the baseline aortic valve area (AVA). The numbers along each curve indicate the rates of heart failure at 5 and 8 years. Note the excess heart failure incidence associated with an AVA less than $1.0 \mathrm{~cm}^{2}$.
$35 \%, P<.001)$. Multiple reasons were cited as justification for not performing AVR, including AS judged not severe $(57 \%)$ mostly based on low gradient, patient's age too great (24\%), comorbidities $(37 \%)$, symptoms judged equivocal $(43 \%)$, patients with no interest in surgery $(20 \%)$, and physician choice $(20 \%)$. Patients with an AVA less than $1.0 \mathrm{~cm}^{2}$ with discordant versus concordant velocity/gradient underwent less valve replacement (5-year incidence, $44 \% \pm 9$ vs $69 \% \pm 9 \% ; P<.001$ ) and had lower overall (including postoperative) survival (5-year survival, $47 \% \pm 7$ vs $69 \% \pm 8 \% ; P=.01$ ), even after adjustment (adjusted RR, 1.67; 95\% CI, 1.01-2.81; $P=.04$ ) for age, sex, and EF. Adjusting for age, sex, EF, Charlson co-morbidity index, and AVA, AVR was associated with subsequent decreased mortality (adjusted RR, 0.61; 95\% CI, 0.39-0.94; $P=.02$ ) and CHF (adjusted RR, 0.29; 95\% CI, 0.13 $0.64 ; P<.01)$, irrespective of the gradient $(P>.40)$.

\section{DISCUSSION}

This first comprehensive study of patients with AS diagnosed in a community medical practice revealed new information on the current presentation and outcomes of patients with AS. In the current era, AS is first diagnosed in an elderly population whose presentation is challenging. Despite the exclusion of severe comorbidities, symptoms were frequent, were not linked to AS severity, and were insensitive outcome predictors. Also, severe AS most often presented with a low gradient despite a normal EF, leading to potential underestimation of its severity. The preeminent and most sensitive objective marker of outcome was an AVA of less than $1.0 \mathrm{~cm}^{2}$, even in patients with low-gradient AS despite a normal EF. An AVA of less than $1.0 \mathrm{~cm}^{2}$ was associated with excess mortality and $\mathrm{CHF}$, even in asymptomatic patients. AVR markedly reduced the risk of death or $\mathrm{CHF}$ but was performed in few patients with severe stenosis, particularly those with low-gradient AS. Although in elderly patients, individualized clinical decisions are warranted, awareness that an AVA of less than $1.0 \mathrm{~cm}^{2}$ implies a high risk, irrespective of symptoms or gradient, should lead patients with confirmed severe AS to carefully and individually consider AVR.

\section{Challenging Presentation of AS in the Community}

Although AS is a classic valve disease, epidemiologic changes $^{2}$ have profoundly affected this supposedly wellknown condition. Currently, AS is usually degenerative and affects the elderly, ${ }^{2}$ deeply contrasting with the mid20th century predominance of rheumatic stenosis affecting patients typically 50 to 60 years old. ${ }^{15}$ Our results have shown that the constructs developed in the $1960 \mathrm{~s}^{8}$ of patients with high-gradient AS remaining asymptomatic for a long period and then developing clearly defined symptoms heralding poor outcomes, are not congruent with current realities. The current challenging AS presentation could not 
be uncovered in referral center studies, ${ }^{6,9,10}$ which segmented a priori AS subsets rather than comprehensively enrolling all patients. With advancing age at diagnosis, comorbidities and inactivity hinder symptom assessment. With all cases of diagnosed AS gathered, we noted that symptoms labeled as cardiac symptoms are frequent and not specific to AS severity. Thus, the mediocre quality of the link between symptoms and outcome is logical. Furthermore, the disconnection between symptoms and surgical referral does not reveal poor clinical practice but rather the difficult interpretation of a challenging presentation. Another presentation challenge is the frequency of severe AS with a low gradient. A low gradient resulting from a low EF and its poor prognosis is well known ${ }^{16}$; however, severe AS with a low gradient owing to a lower stroke volume despite a normal EF is less recognized. This entity was recently emphasized $^{11}$ but has been disputed out of concern for calculation inaccuracy, ${ }^{17}$ because an underestimation of the aortic annular diameter could lead to a spuriously low AVA. However, these technical concerns are superseded by the observed outcomes in the community, demonstrating, despite a benign appearance, that this particular form of AS has a poor prognosis ${ }^{11}$ that is alleviated by AVR. ${ }^{11}$ Nevertheless, this challenging presentation leads to hesitations in indicating surgical treatment that has major implications for the outcomes.

\section{Outcome of AS in the Community}

Series from referral centers affected by selection biases $^{6,9,10}$ showed wide discrepancies in 5-year survival of $38 \%$ to $83 \%$ and outcomes qualified as benign to malignant. ${ }^{6,9,10}$ Discrepancies can also stem from short follow-up ${ }^{9}$ and the selection of young patients. ${ }^{9}$ Our comprehensive community study has shown that AS is a serious disease, with excess mortality increasing progressively after diagnosis with an AVA of less than $1.0 \mathrm{~cm}^{2}$, generally leaving time to give careful consideration to therapeutic options. Our community study of all patients with AS has shown that the theoretical constructs of low- and high-risk subsets according to the symptoms or gradient, although conceptually attractive, ${ }^{3}$ were not successful in reality as predictors of outcome. "Asymptomatic" patients, long considered at low risk, ${ }^{8}$ incur notable risks of sudden death ${ }^{6}$ and longterm mortality, ${ }^{6,10}$ possibly because of underestimated functional impairment. ${ }^{18}$ Symptoms, when present, were not helpful in determining the prognosis and were not specific of severe AS. In our series, only class III-IV symptoms predicted mortality but were insensitive and not AS specific. Our data do not obviate the need for surgery in severe AS with class III-IV symptoms ${ }^{3}$ but emphasize the limitations of a watchful symptom-based approach. ${ }^{9}$

In this era of poor symptom reliability, resulting from age, inactivity, or comorbidity, it is essential to define clearly objective risk markers. A low EF is a wellestablished high-risk marker that was confirmed in our community ${ }^{16}$ However, the risks attached to low EF persist after surgery ${ }^{19}$ such that intervening at that stage is required but not desirable. Doppler measures have been disputed. Some studies used peak velocity, ${ }^{6,9}$ others the $\mathrm{AVA}^{10,18}$ or more complex indexes, ${ }^{20}$ with variable thresholds and none have compared the value of these markers. Our data with a minimized referral bias have shown that an AVA of less than $1.0 \mathrm{~cm}^{2}$ is the preeminent, powerful, and sensitive marker of mortality and CHF. The greater sensitivity of an AVA less than $1.0 \mathrm{~cm}^{2}$ is related to the detection of patients at high risk despite the combination of a low gradient and normal EF. However, in clinical practice, considering surgery in elderly patients with low-gradient AS requires confirmation that the aortic valve disease is severe using either catheterization or new noninvasive computed tomography quantitation of aortic valve calcification load. ${ }^{21}$ This technique measures the intrinsic valve lesion mechanistic to $\mathrm{AS}^{22}$ and is simple, accurate, and clinically relevant. ${ }^{21}$ Thus, in elderly patients, confirming severe AS is possible according to either high gradient or high calcification load (in those with low-gradient AS), which has important implications for the indication of AVR.

\section{AVR and Outcomes}

Medical therapy is ineffective in preventing stenosis progression, and AVR is the only approved treatment of AS. ${ }^{3}$ It markedly reduces mortality and $\mathrm{CHF}$ and has low operative risk $^{19}$; however, it is often delayed or not performed in severe AS, even with severe symptoms. ${ }^{4,6,10,16}$ Emphasis has been placed on the hazard of overestimating surgical risk; however, surgical deferral might be appropriate in some very elderly patients with overwhelming comorbidity. ${ }^{23}$ However, most often the nonindication for AVR results from the challenging presentation, involving poorly decipherable symptoms and/or low-gradient AS. ${ }^{11}$ In the future, this unmet need for treatment might be better addressed by further declining operative risks ${ }^{23}$ and by new percutaneous valve replacement. ${ }^{24}$ With problematic symptom assessment and serious outcome consequences of an AVA less than $1.0 \mathrm{~cm}^{2}$ even without symptoms, we believe a more proactive approach to AS should be considered. Obtaining confirmation of AS severity with an AVA of less than $1.0 \mathrm{~cm}^{2}$ and low gradient is essential to timely discuss surgical treatment individualized to the patient's age and comorbidities.

\section{Study Limitations}

Our series is not the largest assessing the outcomes of AS. ${ }^{6,10}$ Our large referral practice would considerably increase the sample but with the limitations of referral bias. ${ }^{25}$ Data from an entire community medical practice ${ }^{25}$ have reconciled previous widely variable survival estimates 
from referral centers and the high event numbers provided ample power. Determining the cause of death in an elderly population and its link to AS was not consistently feasible. However, the mortality-severity association and the exclusion of severe comorbid conditions support a link between severe AS and excess mortality after diagnosis. The retrospective identification and chart review is a limitation but offers the only option to identify all community patients with AS in a large practice. The recommendation for AVR was determined by the personal physicians and not from a predefined strategy. ${ }^{3}$ Thus, our study could not reveal the advantages of 1 treatment strategy over another but measured the performance and effect of AVR on outcomes in routine medical practice.

\section{CONCLUSIONS}

In the community, AS generally affects the elderly with a challenging presentation. Symptoms are frequent but often discordant with AS severity and are problematic to interpret. Furthermore, severe AS often presents with a low gradient despite a normal EF. In predicting the outcome, symptoms (class III-IV) are insensitive risk markers. An AVA of less than $1.0 \mathrm{~cm}^{2}$ is the most powerful and sensitive predictor of severe outcomes with a close to doubling of death and CHF risk and excess mortality compared with that expected. The excess risk attached to AVA of less than $1.0 \mathrm{~cm}^{2}$ was present even in those without symptoms and/or with low-gradient AS. AVR improves outcome but is performed in few patients, particularly among those with a low gradient despite severe AS. Thus, the presently demonstrated challenging presentation and incompletely met need for treatment of AS suggest that, in patients with an AVA of less than $1.0 \mathrm{~cm}^{2}$, a thorough evaluation and prudent AVR considerations are warranted.

\section{References}

1. Butany J, Collins MJ, Demellawy DE, Nair V, Israel N, Leong SW, et al. Morphological and clinical findings in 247 surgically excised native aortic valves. Can J Cardiol. 2005;21:747-55.

2. Nkomo VT, Gardin JM, Skelton TN, Gottdiener JS, Scott CG, EnriquezSarano M. Burden of valvular heart diseases: a population-based study. Lancet. 2006;368:1005-11.

3. Bonow RO, Carabello BA, Kanu C, de Leon AC Jr, Faxon DP, Freed MD, et al. ACC/AHA 2006 guidelines for the management of patients with valvular heart disease: a report of the American College of Cardiology/American Heart Association Task Force on Practice Guidelines (writing committee to revise the 1998 Guidelines for the Management of Patients with Valvular Heart Disease): developed in collaboration with the Society of Cardiovascular Anesthesiologists: endorsed by the Society for Cardiovascular Angiography and Interventions and the Society of Thoracic Surgeons. Circulation. 2006;114:e84-231.
4. Iung B, Cachier A, Baron G, Messika-Zeitoun D, Delahaye F, Tornos P, et al. Decision-making in elderly patients with severe aortic stenosis: why are so many denied surgery? Eur Heart J. 2005;26:2714-20.

5. van Geldorp MW, van Gameren M, Kappetein AP, Arabkhani B, de Groot-de Laat LE, Takkenberg JJ, et al. Therapeutic decisions for patients with symptomatic severe aortic stenosis: room for improvement? Eur J Cardiothorac Surg. 2009;35:953-7.

6. Pellikka PA, Sarano ME, Nishimura RA, Malouf JF, Bailey KR, Scott CG, et al. Outcome of 622 adults with asymptomatic, hemodynamically significant aortic stenosis during prolonged follow-up. Circulation. 2005;111:3290-5.

7. Minners J, Allgeier M, Gohlke-Baerwolf C, Kienzle RP, Neumann FJ, Jander N. Inconsistencies of echocardiographic criteria for the grading of aortic valve stenosis. Eur Heart J. 2008;29:1043-8

8. Braunwald E. On the natural history of severe aortic stenosis. J Am Coll Cardiol. 1990;15:1018-20.

9. Rosenhek R, Binder T, Porenta G, Lang I, Christ G, Schemper M, et al. Predictors of outcome in severe, asymptomatic aortic stenosis. $N$ Engl J Med. 2000;343: 611-7.

10. Pai RG, Kapoor N, Bansal RC, Varadarajan P. Malignant natural history of asymptomatic severe aortic stenosis: benefit of aortic valve replacement. Ann Thorac Surg. 2006;82:2116-22.

11. Hachicha Z, Dumesnil JG, Bogaty P, Pibarot P. Paradoxical low-flow, low-gradient severe aortic stenosis despite preserved ejection fraction is associated with higher afterload and reduced survival. Circulation. 2007;115:2856-64.

12. Bermejo J, Odreman R, Feijoo J, Moreno MM, Gomez-Moreno P, GarciaFernandez MA. Clinical efficacy of Doppler-echocardiographic indices of aortic valve stenosis: a comparative test-based analysis of outcome. J Am Coll Cardiol. 2003;41:142-51.

13. Oh JK, Taliercio CP, Holmes DR Jr, Reeder GS, Bailey KR, Seward JB, et al. Prediction of the severity of aortic stenosis by Doppler aortic valve area determination: prospective Doppler-catheterization correlation in 100 patients. J Am Coll Cardiol. 1988;11:1227-34.

14. Kattan MW. Evaluating a new marker's predictive contribution. Clin Cancer Res. 2004;10:822-4.

15. Horstkotte D, Loogen F. The natural history of aortic valve stenosis. Eur Heart J. 1988;9(Suppl E):57-64.

16. Pereira JJ, Lauer MS, Bashir M, Afridi I, Blackstone EH, Stewart WJ, et al. Survival after aortic valve replacement for severe aortic stenosis with low transvalvular gradients and severe left ventricular dysfunction. J Am Coll Cardiol. 2002; 39:1356-63.

17. Poh KK, Levine RA, Solis J, Shen L, Flaherty M, Kang YJ, et al. Assessing aortic valve area in aortic stenosis by continuity equation: a novel approach using realtime three-dimensional echocardiography. Eur Heart J. 2008;29:2526-35.

18. Das P, Rimington H, Chambers J. Exercise testing to stratify risk in aortic stenosis. Eur Heart J. 2005;26:1309-13.

19. Mihaljevic T, Nowicki ER, Rajeswaran J, Blackstone EH, Lagazzi L, Thomas J, et al. Survival after valve replacement for aortic stenosis: implications for decision making. J Thorac Cardiovasc Surg. 2008;135:1270-9.

20. Otto CM. Valvular aortic stenosis: disease severity and timing of intervention. $J$ Am Coll Cardiol. 2006;47:2141-51.

21. Messika-Zeitoun D, Aubry MC, Detaint D, Bielak LF, Peyser PA, Sheedy PF, et al. Evaluation and clinical implications of aortic valve calcification measured by electron-beam computed tomography. Circulation. 2004;110:356-62.

22. Normand J, Loire R, Zambartas C. The anatomical aspects of adult aortic stenosis. Eur Heart J. 1988;9(Suppl E):31-6.

23. Gehlot A, Mullany CJ, Ilstrup D, Schaff HV, Orzulak TA, Morris JJ, et al. Aortic valve replacement in patients aged eighty years and older: early and long-term results. J Thorac Cardiovasc Surg. 1996;111:1026-36.

24. Webb JG, Pasupati S, Humphries K, Thompson C, Altwegg L, Moss R, et al. Percutaneous transarterial aortic valve replacement in selected high-risk patients with aortic stenosis. Circulation. 2007;116:755-63.

25. Melton LJD. Selection bias in the referral of patients and the natural history of surgical conditions. Mayo Clin Proc. 1985;60:880-5. 